\title{
Magnitudes of South Africa's labour market, 2002-2020 and social implications
}

\author{
Eric O. Udjo \\ Bureau of Market Research, University of South Africa \\ P. O. Box 392, UNISA 0003, South Africa \\ E-mail: udjoe@unisa.ac.za ${ }^{1}$
}

\section{Introduction}

Knowledge about labour market size has several uses. From an economic and development perspective, it can be used as a framework to inform policies in human resource planning at micro- and macrolevels for efficient production of goods and services so as to enhance the wellbeing of people in a society [see Sinz (1984), Lindley (1988), Psacharopoulos (1991), Neugart and Schomann (2002), Reinberg and Markus (2002), Ehrenberg (2003)]. Knowledge of the future size of the labour market is also valuable in employment creation strategies. Widespread concern about economic and development planning in both industrialised and less developed countries has led to increasind in interest and efforts in preparing estimates of economic characteristics of the population. Furthermore, estimates of the economically active population are needed to give an indication of the number and characteristics of the workers that will be available for employment in future years so that appropriate plans and policies can be made (Shryock, Siegel and Associates, 1976). Without adequate information about the magnitudes of the future labour force, it is difficult to assess whether there are sufficient jobs to absorb the future size of the labour force. Thus, knowledge of the magnitudes of the future labour force is essential to planning to reduce potential unemployment and its social consequences.

From a demographic perspective, labour market estimates provide insights into labour market effects including ageing of the labour force and the dependency burden due to demographic transition [see Borsch-Supan (200I)]. In market research, the size of the labour market is one of the determinants of market potential and thus knowledge about the future size of the labour market facilitates decision making regarding whether to produce and where to market certain products in the future. Despite needs mentioned above, information about probable future magnitudes of labour market size and characteristics is often lacking.

\subsection{Labour market studies on South Africa}

A number of studies have been carried out on the labour market in South Africa. The following highlight some of the studies. Reviewing the labour markets in South Africa, Altman (2005) noted that the labour market landscape has changed dramatically over the first decade of democratic governance with an emphasis being placed on strategies that eliminate the labour inequalities of the past and improve general working conditions for all South Africans (SouthAfrica Info, 2012). Burger and Jafta (2006) assessed the impact of post 1994 policy, specifically affirmative action policy on post-apartheid labour market in South Africa and concluded that affirmative action policies have not been successful in its aim to redress the disadvantages in employment experienced by designated groups or to ensure their equitable representation in all occupational categories and levels in the workforce. They further argued that affirmative action may be influencing labour market outcomes by focusing attention on representation at the top end of the occupational ladder. According to Bhorat and Oosthuizen (2004), the most important challenge facing South African economy is the challenge of generating job opportunities in sufficient numbers so as to half the rise in unemployment and then to reduce it. They argue that equality in the labour force is still way off in terms of access to employment.

Focusing on the elderly and using the 1996, 2001 censuses, labour force surveys as well as Income and Expenditure survey, Lam, Leibbrfandt and Ranchhod (2005) observed that labour force participation rates fall fairly rapidly after age 45 , particularly sharp declines in both participation and work at the age of eligibility for the old-age pension. Regarding women in the labour market in South Africa, Ndungu (20I0) argues that not only do women experience a higher rate of unemployment compared to men, but women also make up about two of every three discouraged work seekers. Ndungu further argued that the recent economic crisis has also disproportionately affected women, with the number of females who are no longer economically active rising sharply between 2008 and 2009. They point out that historically, the South African labour market excluded women from almost completely from participating in

I. Tel: +27 I2 429 3326, Fax: +27 4296225 
the economy but that since 1995, slightly over two million women have found employment.

Altman (2005) has noted some limitations in labour labour market studies in South Africa. According to Altman, labour market analysis in South Africa distinguishes the formal sector and the informal sector with studies rarely considering them together. No such distinction is made in the present study. Altman has also noted that although it is well known that HIV has spread in South Africa, analysis of labour market trends in South Africa rarely include the HIV/AIDS pandemic. As can be seen from the methods section, this study incorporates HIV/AIDS. Aside the limitations noted by Altman, labour market analysis in South Africa generally focus on the past and the present and rarely focus on the future.

\subsection{Aim of study}

The aim of this study is to estimate the probable future magnitudes (up to 2020) of South Africa's labour market size and age-sex structure disaggregated by the four main population groups - Africans, coloureds (persons of mixed descent), whites and Asians. [Official figures (Statistics South Africa - Stats SA, 2007) suggest that Africans currently constitute about $79.0 \%$, coloureds $9.0 \%$, Asians $2.6 \%$, and whites $9.5 \%$ of South Africa's population.] The study also draws attention to the social implications of large numbers of unemployed persons likely to accompany an increasing labour force in South Africa.

\section{Definition of concepts}

The labour force concepts employed in the present study are defined as follows:

Labour force is the population aged $15-64$ years whose members are available for work whether currently employed or unemployed. The labour force therefore comprises persons who are currently employed plus persons who are unemployed. Thus the labour force comprises the economically active population. Although the reference age in this study is 15-64 years, the minimum legal age of employment in South Africa is 16 years. While retirement age in many organisations in South Africa is 65 years, some organisations have retirement age as 60 years (usually by negotiation with relevant trade unions).

\subsection{Economically active population}

Expanded definition: The economically active population is defined as people who either worked during the last seven days prior to interview or who did not work during the last seven days prior to interview but want to work and are available to start work within a week of the interview whether or not they have taken steps to look for work or to start some form of self-employment in the four weeks prior to interview [see Stats SA (1998)]. People in employment also include those who are temporarily absent in that they did not work in the last seven days but definitely had a job to return to.

The strict definition excludes from the economically active population persons who have not taken steps to look for work or to start some form of selfemployment in the four weeks prior to interview (Stats SA, 1998). The expanded definition is employed in this study instead of the strict definition because it appears more realistic since it would include unemployed discouraged job seekers who would be willing to work if offered employment.

\subsection{Not economically active population}

The not economically active population comprises those not available to work and includes students, home-makers such as housewives and pensioners. Persons who are not economically active (ie those not available for work) are not in the labour market.

Labour force participation rate (or more correctly, labour force participation ratio) is the ratio of the economically active population (aged $15-64$ years) to the midyear population aged $15-64$ years. The labour force participation rate is therefore the percentage of the working age population which is economically active. In a cohort component population estimate (see section on methods), the labour force participation rate is the labour force percentage of the working age population for a defined fiveyear age group. The labour force participation rate would be slightly affected by legal restrictions with regard to minimum legal age of employment as well as legal age of retirement in different settings.

\section{Data}

The time series employment statuses used in the modelling in this study were derived from South Africa's 1996 and 200I Population Censuses (Stats SA, 1998; 200I) and the 2007 Community Survey (Stats SA, 2007) and 2008 Labour Force Surveys (Stats SA, raw data). This makes interpretation of time trends easier as the choice of these data reduces erratic fluctuations usually observed in time series data. Focusing on all the time series data of the labour force surveys would yield more erratic fluctuations in the trends making the indicators difficult to interpret. The wording of the questions relating to the labour force especially with regard to employment was different in the 1996 compared to the 200I Population Census, 2007 Community Survey and 2008 Labour Force Surveys. Where there was no reference period included in the 1996 census - Does this person work for pay, profit or family 
gain? - a reference period of 7 days was included in the other enquiries - In the last seven days, did this person do any work for a wage, salary, commission or payment in kind? Strictly therefore, the employment question in the 1996 census is not comparable to the 200I Population Census or later surveys. However, since expanded definition of the economically active population was used in the present study, and since this population can be deduced in a similar manner from the various data sets utilised in this study, the labour force derived from the data sets can be compared.

\section{Methods}

The ability to produce sufficient goods and services at any given time depends on land, capital and the size and quality of the labour force. Quality in this context may be seen in terms of: (i) the skills obtained by the labour force through formal education and training, and experience acquired in various types of jobs over time; and (ii) the health status of the labour force. Measures of the skills levels of the labour force can be derived from censuses and cross-sectional surveys and on the basis of these measures, appropriate plans and policies can be formulated to equip and improve the skill levels of the future labour force. Similarly, indicators of the health status of the labour force can be derived from the analysis of time trends in mortality, based on responses to appropriate mortality questions in censuses and surveys in the absence of reliable vital registration systems. It is difficult to establish the current and future size of the labour force because the labour force is inherently dynamic. Yet this information is vital for assessing the size of the job market in terms of planning for job creation. Part of the difficulty in establishing the size of the labour force at any given time is the lack of data.

In the context of South Africa, Stats SA attempts to provide information on the current size of the labour force on a regular basis through its various surveys including the former October Household Surveys (OHS), General Household Surveys (GHS) and more recently, its Quarterly Labour Force Survey (QLFS) (Stats SA, 20II). However, these surveys, as similar surveys elsewhere in the world, do not provide indications of the future size of the labour force in South Africa.

There are a variety of approaches in estimating the future size of the labour force including mathematical, population demand and population supply methods. Mathematical methods entail fitting one form of mathematical curve or the other to the total labour force from two or more sources. One of the weaknesses of mathematical methods is that it cannot be used easily to produce a breakdown of the structure of the labour force. Another approach is "population demand" projections based on labour force needs of a projected economy (Kono, 1993). This is a non-demographic approach and requires a special model of the sectors being projected (Kono, 1993). A third approach is "population supply" and entails estimating the "population supply" of persons eligible to be in a particular functional category in the future based on assumed birth, death and migration rates (Kono, 1993). This approach was utilised in this study and is described in detail in the next section. According to Kono (1993), despite their many limitations, population supply functional projections have a better record of predicting the future than population demand projections.

\subsection{The model}

The estimation of the size of the labour force at any given time may be regarded as a form of functional population estimate. A functional population estimate is an age-sex population estimate that has been transformed or otherwise incorporated into formulas that forecast future supply or demand for some particular purpose (Kono, 1993). The basic approach in functional population estimates in the context of labour force estimates is a two-stage process: first, a cohort component estimate of the population and secondly, estimating the size of the labour force using labour force participation rates. The labour force participation rates together with the size of the population determine the future size of the labour force. At a broad level, the size of the labour force at any given point in time may be estimated as:

$L F(t+n)=P(t+n) . \operatorname{LFPR}(t+n)$

\section{Where:}

$t$ is the initial time period, $t+n$ is the end of the time period interval, $L F_{(t+n)}$ is the estimated number of persons in the labour force at the end of the interval, $P_{(t+n)}$ is the number of persons in the population at the end of the interval, $\operatorname{LFPR}_{(t+n)}$ is the labour force participation rate during the interval.

By extension, for any particular age and sex group, the estimated number of persons in the labour force at time $t+n$ is expressed as:

$L F_{(i, s, t+n)}=P_{(i, s, t+, n)} \cdot \operatorname{LFPR}_{(i, s, t+, n)} \ldots \ldots \ldots \ldots \ldots(2)$

Where $i, s$, refer to a particular age and sex group respectively [see United Nations (1990) for details]. Thus, a cohort component model of estimating the size of the labour force applied in the present study, is expressed as 
$L F=\sum_{x=15}^{64}\left(P_{s, x} . L F P R_{s, x}\right)$

Where $L F$ is the sum of the labour force in each fiveyear age group from 15 - 64 for a sex group at different levels of disaggregation (such as population group).

\subsection{Demographic input}

It is clear from equations I-3 above that in order to estimate $L F_{(t+n),} L F_{(i, s, t+n)}$ and $L F, P_{(t+n)}$ or $P_{(i, s, t+, n)}$ must first be estimated. The cohort component method is usually the preferred method for deriving $P_{(t+n)}$ or $P_{(i, s, t+, n)}$ because of its greater reliability than other methods and it entails estimating, separately, mortality, fertility and net migration. This approach was therefore adopted in the present study. The technical procedure for the cohort component method for deriving $P_{(t+n)}$ or $P_{(i, s, t+, n)}$ has been given by Preston, Heuveline and Guillot (200I). Assumptions about future levels of fertility, mortality and net migration were based on extrapolation of past and current levels using regression methods.

\subsection{Incorporating HIV/AIDS}

Conventional model life tables do not take into account the 'hump' in the age pattern of mortality due to increased AIDS-attributable deaths in young adult ages as these standard mortality schedules were developed prior to the HIV/AIDS epidemic. Standard mortality schedules that take into account HIV/AIDS were developed recently - the INDEPTH model life tables for sub-Saharan Africa (INDEPTH Network, 2004). This was used in the present study to incorporate the impact of HIV/AIDS in the estimates.

\subsection{Past levels and trends in labour force participation rates}

As seen in equations 1-3 labour force participation rates are the principal drivers of the current and future size of the labour force. Estimates of the labour force are partly based on assumptions about future labour force participation rates derived from the analysis of past levels and trends in observed labour force participation rates. Such analysis is presented in the following section.

Figure I shows overall labour force participation rates during the period 1996-2008 in South Africa based on South Africa's 1996 Census (Stats SA, 1998), the 2007 Community Survey (Stats SA, 2007) and 'quarter four' 2008 Labour Force Survey (Stats SA, raw data).

Figure 1: Overall labour force participation rates (\%) by sex (age 15 - 64), 1996 - 2008

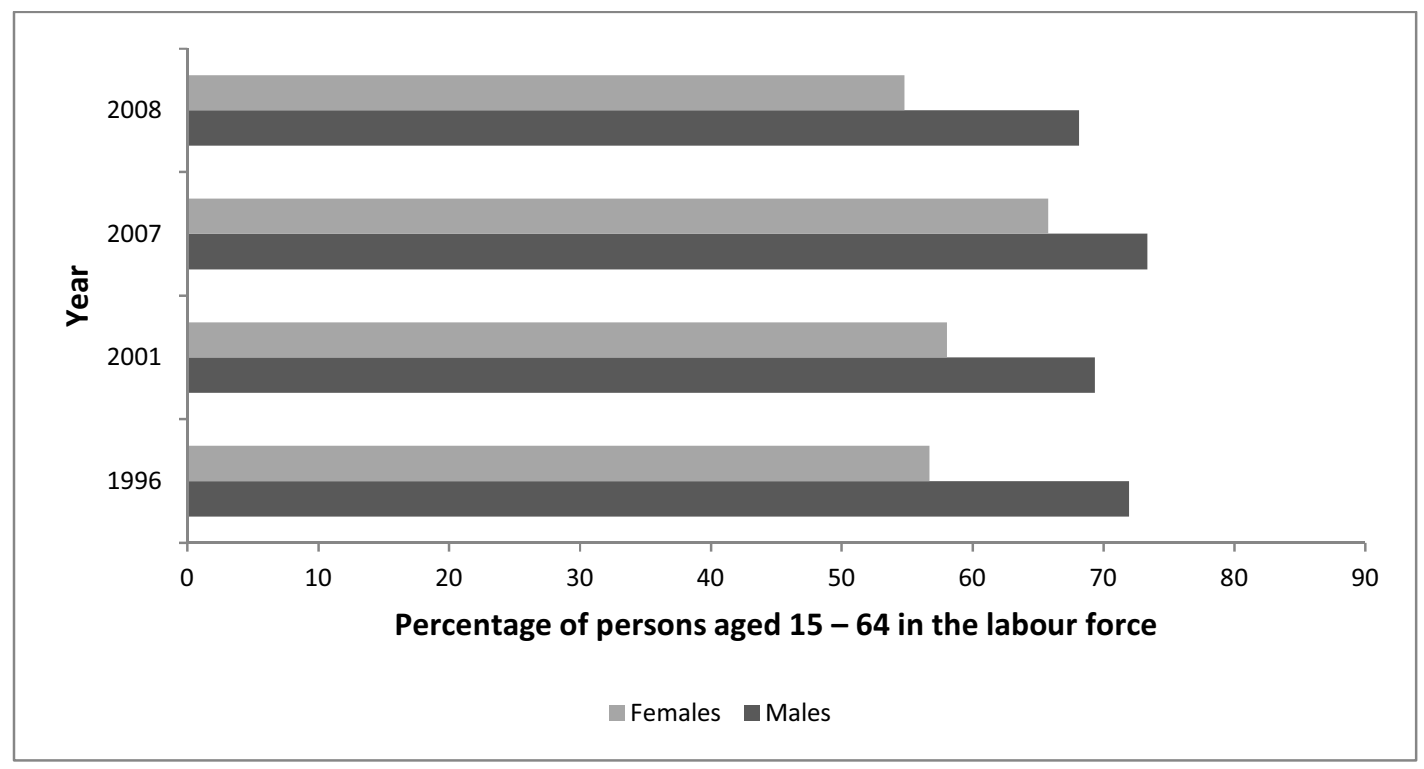

Sources: Computed from 1996 \& 2001 South Africa Censuses (Stats SA, 1998; 2001), 2007 Community Survey (Stats SA, 2007) \& 2008 Labour Force Survey (Stats SA raw data). 
As seen in the graph, the percentage of females in the labour force was much lower than the corresponding percentage of males during the specified periods. Whereas, on average, about $71 \%$ of males aged 15-64 years were in the labour force during the period (1996-2008), the corresponding percentage of females was $59 \%$. Overall in absolute terms, the labour force participation rates were lower in 2008 compared with the labour force participation rates in 2007. The decline in labour force participation rates in 2008 may partly be due to the economic recession that swept through the globe in 2008 some discouraged unemployed persons (but economically active) may be so discouraged that they exit the labour force. They may however become economically active again when the economic recession improves in the future by re-entering the labour force.

Figure 2: relative age-specific labour force participation rate, African males, 1996 - 2008

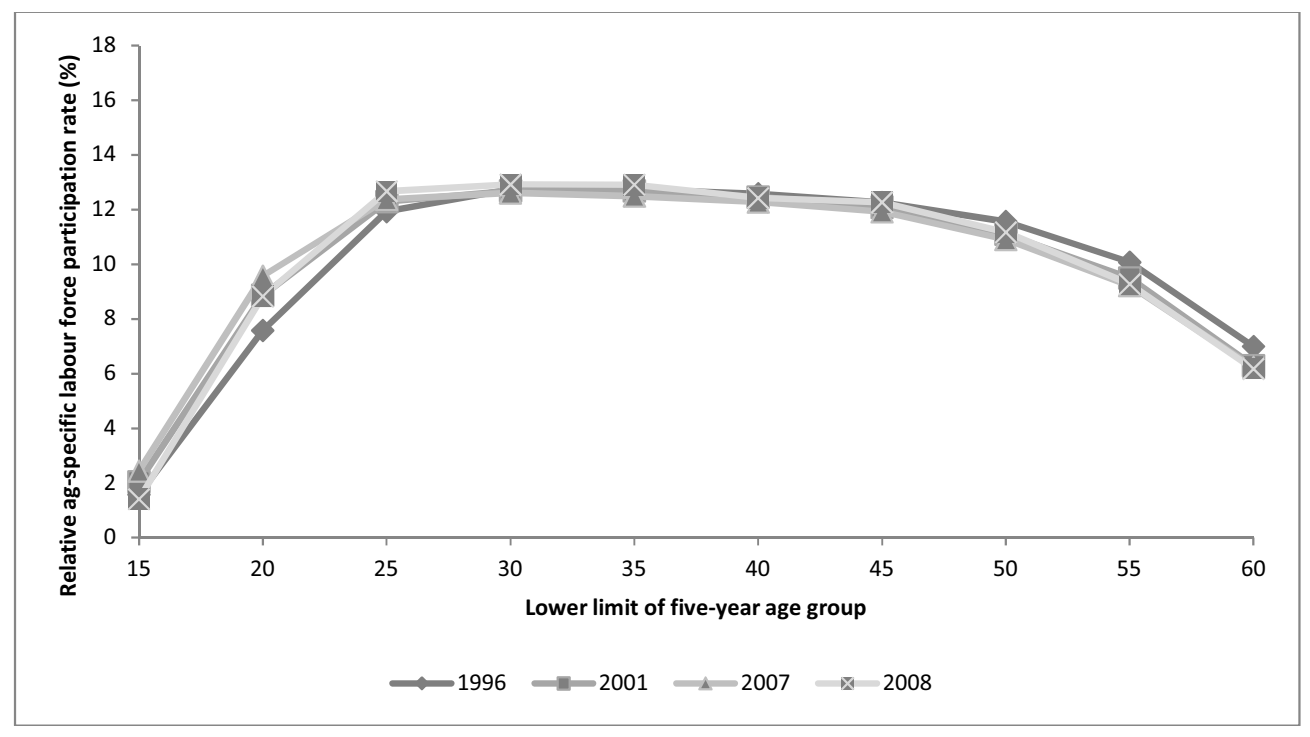

Sources: Computed from 1996 \& 2001 South Africa Censuses (Stats SA, 1998; 2001), 2007 Community Survey (Stats SA, 2007) \& 2008 Labour Force Survey (Stats SA raw data).

Although an overall measure of labour force participation is useful for easy comparison among several subgroups over time, labour force participation rates vary by age due to a number of factors, including changes in life cycles of individuals that operate at different intensities at different ages. For example, under the age of 20 years, labour force participation rates are likely to be low in any population because at this age, a large percentage of people are likely to be in educational institutions. Variations in age specific labour force participation rates as well as population size determine the overall size of the labour force.

Since age structure in non-stable populations and the size of the labour force are not constant over time, it is more appropriate to examine relative agespecific labour force participation rates to control for differences in the size of the labour force as well as changing age structure at different time periods. Thus the relative age-specific labour force participation rate is a measure of the percentage contribution of a five-year age group's contribution to total labour force participation controlling for changing age struc- ture and the total size of the labour force.

The analysis of past trends in age-specific labour force participation rates was disaggregated by the four main population groups (African, coloured, Asian and white) in South Africa since the four groups have different demographic characteristics. The trends for African males are illustrated in Figure 2. The peak of labour force participation was in the age group 30-34 in all population groups except among Coloureds during the period 1996-2008 (graphs not shown). The analysis also indicated that in each population group, there were very slight shifts or changes in the age pattern of labour force participation during the period.

\subsection{Assumptions}

In its simplest form according to Shryock, Siegel and Associates (1976) it might be customary as a scenario to assume that labour force participation rates would remain constant from the last observed rates. They also note however that it is more plausible to allow for some improvement in labour force participation rates in the future labour force. The latter was considered more probable in the context of 
South Africa hence the following assumptions were made in the present study.

Scenario: Improving age-specific labour force participation rates: As noted above, although the relative age specific labour force participation rates showed little shift over time in some age groups in the four population groups, the absolute the age specific labour force participation rates declined during the period 2007 and 2008 in all four population groups probably due to the economic recession of the period. In estimating the future labour force it was assumed in this study that there would be a gradual improvement in the age-specific labour force participation rates each year after 2008 at the levels between 2006 and 2007 (estimated by linear interpolation) till the end of the projection period. It is assumed that this improvement is due re-entry into the labour force of some of those who may have exited previously due to the economic recession. The results of this scenario are presented below.

\section{Results}

\subsection{Estimated overall size of the labour force}

Table I shows the estimated size of the labour force. The estimates indicate that the total size of the labour force could increase from approximately 18.3 million in 2002 to 25.2 million in 2020 in South Africa if the above assumptions held.

The largest scale survey in South Africa undertaken by Stats SA was the 2007 Community Survey (Stats SA, 2007). As a way of evaluating the plausibility of the estimates, the results from the above estimates were compared with the Community Survey result regarding the size of the labour force (using the expanded definition of economically active population) for the reference year of 2007. Whereas Stats SA's figure of the labour force in February 2007 derived from the Community Survey was approximately 20,496,006, the estimate from this study put the size of the labour force in mid-2007 at approximately $20,040,199$. It is comforting that the two figures are close though Stats SA's figure is slightly higher (by about $2 \%$ ) than the figure estimated by this study.

Table I Estimated labour force by population group, 2002-2020

\begin{tabular}{|c|c|c|c|c|c|}
\hline Year & African & Asian & Coloured & White & Total \\
\hline 2002 & $13,573,486$ & 487,252 & $1,852,364$ & $2,386,007$ & $18,299,109$ \\
\hline 2003 & $14,006,523$ & 497,612 & $1,898,385$ & $2,410,856$ & $18,813,376$ \\
\hline 2004 & $14,453,376$ & 508,192 & $1,945,549$ & $2,435,964$ & $|9,343,08|$ \\
\hline 2005 & $|4,9| 4,484$ & 518,997 & $1,993,885$ & $2,461,333$ & $19,888,699$ \\
\hline 2006 & $14,989,539$ & 522,095 & $2,004,190$ & $2,448,366$ & $19,964,190$ \\
\hline 2007 & $15,064,972$ & 525,212 & $2,014,548$ & $2,435,467$ & $20,040,199$ \\
\hline 2008 & $15,140,784$ & 528,348 & $2,024,959$ & $2,422,636$ & $20,116,727$ \\
\hline 2009 & $15,216,978$ & 531,502 & $2,035,425$ & $2,409,872$ & $20,193,777$ \\
\hline 2010 & $15,293,555$ & 534,675 & $2,045,944$ & $2,397,176$ & $20,27 I, 350$ \\
\hline 2011 & $15,708,250$ & 546,447 & $2,093,202$ & $2,402,039$ & $20,749,938$ \\
\hline 2012 & $16,134,189$ & 558,477 & $2,|4|, 552$ & $2,406,912$ & $21,24 I, 130$ \\
\hline 2013 & $16,571,679$ & 570,773 & $2,191,019$ & $2,4 I I, 795$ & $21,745,266$ \\
\hline 2014 & $|7,02|, 03 \mid$ & 583,339 & $2,24 I, 628$ & $2,416,688$ & $22,262,686$ \\
\hline 2015 & $17,482,567$ & 596,182 & $2,293,406$ & $2,421,591$ & $22,793,746$ \\
\hline 2016 & $17,897,679$ & 607,553 & $2,336,161$ & $2,40 I, 676$ & $23,243,069$ \\
\hline 2017 & $18,322,648$ & 619,141 & $2,379,712$ & $2,381,925$ & $23,703,426$ \\
\hline 2018 & $18,757,708$ & 630,951 & $2,424,076$ & $2,362,337$ & $24,175,072$ \\
\hline 2019 & $19,203,098$ & 642,985 & $2,469,267$ & $2,342,910$ & $24,658,260$ \\
\hline 2020 & $19,659,063$ & 655,249 & $2,515,300$ & $2,323,642$ & $25,153,254$ \\
\hline
\end{tabular}




\subsection{Estimated size of the labour force by population group and sex}

As seen in Table I, it is estimated that the size of the labour force would:

- increase from 13.6 million in 2002 to 17.4 million in 2015 and 19.7 million in 2020 among Africans;

- increase from 487,252 in 2002 to 596,182 in 2015 and 655,249 in 2020 among Asians;

- increase from 1.9 million in 2002 to 2.3 million in 2015 and 2.5 million in 2020 among coloureds;

- decrease from 2.4 million in 2002 to 2.3 million in 2020 among whites. The estimated decrease in the size of the labour force among whites is due to the low levels of fertility (below replacement levels of fertility) as well as emigration experienced by whites.

A sex ratio (number of males divided by the number of females) of the labour force provides and indicator of the relative size of the male female labour force. In absolute terms, the estimated male labour force was larger than the female labour force in each population group in each year of the period estimates despite the higher number of females relative to males in each population group (except among whites, where the numbers were similar) in the general population aged 15-64 in each of the period estimates. This study estimates that, by 2020 , the male labour force among Africans would be about 10\% larger than the female labour force, down from 13\% in 2002. This implies that the difference in the size of the male and female labour force is estimated to get narrower over time. A similar pattern is estimated among the other population groups.

\subsection{Estimated growth of the labour force}

The estimated annual growth rates of the male and female labour force were positive during the period $2000 / 2005$ among the four population groups but estimated to be negative during the period 2010/ 2015 and 2015/2020 among white males as well as among white females in 2015/2020 (Figure 3). With the exception of whites, the annual growth rates of the labour force were estimated to be positive in mid-2010-2020 for both males and females. On average (for both sexes combined), the estimated annual growth rate of the labour force for the period 2010-2020 was highest among Africans (2.7\%) and least among whites $(0.25 \%)$.

Figure 3: Estimated annual growth rates of the labour force by population group and sex, 2005 - 2020

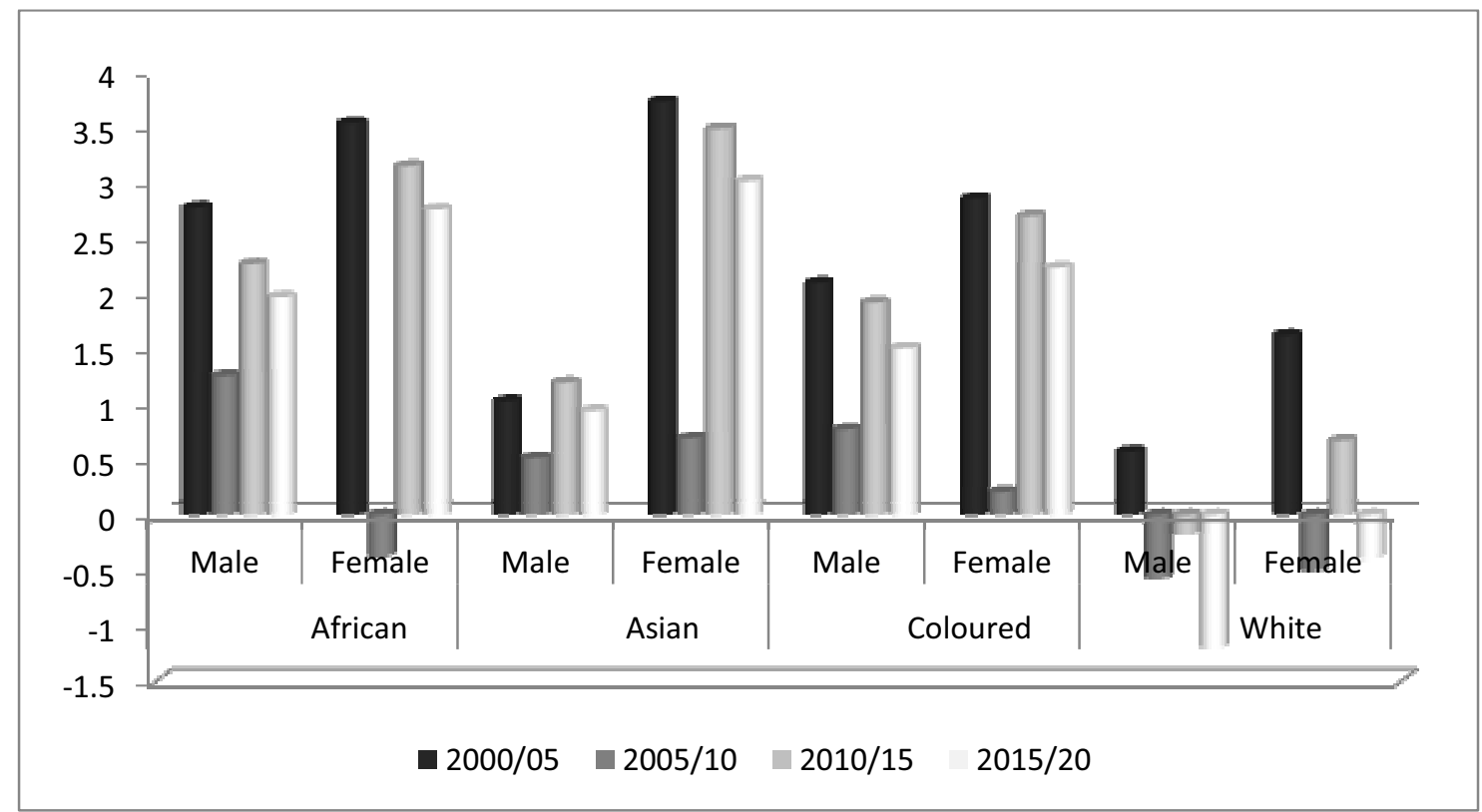

\subsection{Estimated age distribution and median age of the labour force by population group}

The estimated absolute numbers of the labour force by age and population group for 2015 and 2020 are shown in Table 2.

As seen in the table, the absolute numbers of persons in the labour force in each five-year age group are estimated to increase in each of the population groups during the period except among the white population in the age groups 20-24, 25-29 ...45-49. This suggests that in absolute terms there would be increasing numbers of new entrants into the labour force by 2020 from the younger cohort in 
comparison with the number of new entrants into the labour force in 2010 except among the white population. (The white population has a different pattern due to emigration combined with sustained low fertility which is now below replacement level). Consequently, the median age of persons in the labour force is estimated to increase slightly in 2020 compared with the median age in 2010 among all population groups. The estimated median age of the labour force ranges between 34.7 years among Africans in 2010 to 42.5 years among whites in 2020 . The median age is higher among whites because it is an 'older population' (the proportion of older persons is higher among whites than in the other population groups).

Table 2 Estimated size of the labour force by age and population group, 2010 and 2020

\begin{tabular}{|c|c|c|c|c|c|c|c|c|}
\hline \multirow{2}{*}{$\begin{array}{l}\text { Age } \\
\text { group }\end{array}$} & \multicolumn{2}{|l|}{ African } & \multicolumn{2}{|l|}{ Asian } & \multicolumn{2}{|l|}{ Coloured } & \multicolumn{2}{|l|}{ White } \\
\hline & 2010 & 2020 & 2010 & 2020 & 2010 & 2020 & 2010 & 2020 \\
\hline $15-19$ & 386,788 & 586,312 & 18,984 & 22,816 & 86,137 & 96,041 & 32,384 & 51,543 \\
\hline $20-24$ & $2,164,577$ & $2,952,77 \mid$ & 71,928 & 74,622 & 308,266 & 332,385 & 214,499 & $178,90 \mid$ \\
\hline $25-29$ & $2,672,923$ & $3,387,433$ & 75,360 & 89,796 & 332,033 & 398,518 & 303,153 & 272,857 \\
\hline $30-34$ & $2,597,457$ & $3,04 I, 769$ & 81,284 & 99,409 & 284,890 & 363,915 & 329,440 & 276,248 \\
\hline $35-39$ & $2,319,288$ & $2,688,993$ & 73,538 & 83,148 & 285,382 & 326,953 & 313,384 & $25 I, 803$ \\
\hline $40-44$ & I,7I5,279 & $2,399,037$ & 66,950 & 84,101 & 258,733 & 287,863 & 288,273 & 259,456 \\
\hline $45-49$ & $1,392,303$ & $1,985,002$ & 63,346 & 77,696 & 209,340 & 274,197 & 296,881 & 282,254 \\
\hline $50-54$ & $1,039,237$ & $\mathrm{I}, 328,147$ & 42,367 & 56,780 & 150,496 & 218,161 & 263,877 & 274,937 \\
\hline $55-59$ & 698,483 & 851,017 & 29,889 & 46,708 & 96,977 & 153,114 & 228,755 & 274,804 \\
\hline $60-64$ & 307,220 & 438,582 & 11,029 & 20,173 & 33,690 & 64,153 & 126,530 & 200,839 \\
\hline Total & I 5,293,555 & $19,659,063$ & 534,675 & 655,249 & $2,045,944$ & $2,5 \mid 5,300$ & 2397176 & 2323642 \\
\hline
\end{tabular}

\section{Discussion and conclusion}

Labour force estimates have several uses, the most common use being to provide indications of the number of workers that would be available for employment in future years so that appropriate plans and policies can be made (Shryock, Siegel and Associates, 1976). The results of the estimates presented above indicate that the size of the labour force in South Africa would continue to increase in absolute terms at a national level despite negative annual labour force growth rates experienced among females and despite a decline in fertility that South Africa has experienced over the past three decades.

If the age-specific unemployment rates (expanded definition) observed in the fourth quarter of Stats SA's Labour Force Survey in 2008 (Stats SA, raw data) were to remain constant till 2020 the estimates from this study suggest that about 6.6 million persons aged 15-64 years may be unemployed in South Africa by 2020 . However, if the age-specific unemployment rates were reduced by $5 \%$ in each of the age groups the estimated number of persons unemployed aged 15-64 years in 2020 may be approximately 5.3 million while a reduction in the unemployment by $10 \%$ (a rather optimistic sce- nario) in each age group would result in the number of persons unemployed aged 15-64 years in 2020 being 4.1 million. These numbers present challenges for job creation and development in South Africa.

Long term and persistent unemployment in any society has adverse economic and social consequences. According to Gangl (2006), unemployment has negative effects on workers' subsequent earnings and careers as it inflicts persistent scar effects on workers' subsequent career prospects. Using population data, Strait (200I) found that employment dynamics had significant effects on the growth of extreme poverty. In their study, Corcoran and Hill (1980) argued that the number of persons living in poverty would have been reduced by about $10 \%$ if all unemployed household heads had been eliminated. Mroz and Savage (2006) observed that youth unemployment experienced as long as 10 years continued to affect earnings adversely despite a rational catch-up response. At a societal level, economic consequences of long-term and large-scale unemployment include increased spending by the state on various welfare services which might reduce budgetary allocation to other critical sectors of the economy.

A number of negative social consequences are associated with unemployment. Graetz (1993) 
observed that employed people report significantly lower levels of health disorder than the unemployed, which is attributed to employment status rather than predisposing health differences. Furthermore, Hammarstrom (1994) observed that unemployment is a risk indicator for increasing alcohol and tobacco consumption especially among youths. Australian studies cited in Mathers and Schofield (1998) using a wider range of health indicators, indicate worse health among unemployed Australians. At the level of the family, McLoyd (1989) observed that fathers who respond to economic loss with increased irritability and pessimism are less nurturant and more punitive and arbitrary in their interactions with the child and that this might increase the child's risk of socioemotional problems, deviant behaviour, and reduced aspirations and expectations. In a broad review of existing research on the consequences of unemployment for families, Strom (2003) noted that a large number of studies indicate various kinds of adversity are likely to occur among families hit by unemployment, including propensity to divorce or a decline in the the well-being of spouse and children.

The large number of unemployed persons likely to accompany an increasing labour force in South Africa presents challenges to policy makers with regard to job creation. Large-scale unemployment in any society could be a ticking time bomb if appropriate interventions are not made to create sufficient jobs. According to Frank (1968), politicians in power fear a growing mass of urban unemployed and underemployed as a source of political instability.

South Africa constituted about 18\% of the total population of the South Africa Development Community countries (SADC) in 2010, which, besides South Africa, comprises Angola, Botswana, Democratic Republic of Congo, Lesotho, Madagascar, Malawi, Mauritius, Mozambique, Namibia, Seychelles, Swaziland, United Republic of Tanzania, Zambia and Zimbabwe (SADC 20II). South Africa attracts immigrants from especially the SADC countries but the number of immigrants to the total population of South Africa is small.

The 1996 South Africa's census data suggest that the percentage of the total population of South Africa that were foreign born living in South Africa was about $2.4 \%$ and the 2007 Community Survey (Stats SA, 2007) data suggest that this percentage increased to $2.7 \%$ in 2007 . Furthermore, the 2007 Community Survey data suggest that the foreign born population aged I5-64 constituted about 3.4\% of the total population aged 15-64 in South Africa in 2007. Despite these small percentages of foreign born in South Africa, there appears to be a perception of "large numbers" of foreigners in South Africa. There have been reported pockets of attacks against foreign nationals in townships and squatter areas in South Africa in recent years, reportedly partly due to alleged "foreigners taking over their jobs". While the percentage of foreign born living in South Africa has remained under $5 \%$ since 1996, the unemployment rate (expanded definition) is still relatively high in South Africa: about 34\% in 1996 and $30 \%$ in 2007 (Stats SA, 1998; 2007). With such high levels of unemployment and a probable increase in the absolute numbers of unemployed persons in the future, there may be increasing resentment against foreigners by certain sections of South Africa's population and increasing social tension between foreign born and South African born in these sections of the population. While the solution might appear to be a tightening of South Africa's immigration laws, it would appear that a more appropriate solution would be to aggressively implement job creation strategies to sharply reduce rates of unemployment.

\section{Acknowledgement}

I wish to thank Statistics South Africa for providing access to the data. The views expressed in this paper are, however, those of the author.

\section{References}

Altman M, (2005). A review of labour markets in South Africa: Research gaps: labour market function and policy in South Africa. Human Sciences Research Council/ Sida.

Bhorat, H. and Oosthuizen M. (2004). The postapartheid South African labour market. African Development and Poverty Reduction: the MacroMicro Linkage, Forum Paper.

Borsch-Supan, A. H. (200I). Labour market effects of population aging. NBER Working Paper Series Vol w8640.

Burger, R. and Jafta R. (2006). Returns to race: labour market discrimination in post-apartheid South Africa. Stellenbosch Economic Working Papers: 04/06. University of Stellenbosch.

Corcoran, M. and Hill, M. S. (1980). Unemployment and poverty. Social Science Review 54(3), pp. 407413.

Ehrenberg, R. G. (2003). Prospects in the academic labour market for economists. Journal of Economic Perspectives I8(2), pp, 227-238.

Frank, C.R. (Jr). (1968). Urban unemployment and economic growth in Africa. Oxford Economic Papers. New Series 20(2), pp. 250-274.

Gangl, G. (2006). Scar effects of unemployment and assessment of institutional complemarities. American Social Review, 71, pp. 986-1013.

Graetz, B. (1993). Health consequences of employment and unemployment: longitudinal 
evidence for young men and women. Social Science and Medicine 36(6), pp. 7I5-724.

Hammarstrom, A. (1994). Health consequences of youth unemployment - a review from a gender perspective. Social Science and Medicine, 38(5), pp. 699-709.

INDEPTH Network. 2004. INDEPTH model life tables for Sub-Saharan Africa. Farnham: Ashgate Publishing Limited.

Kono, S. (1993). Functional population projections. Editor's introduction. In Readings in population research methodology eds. J. Bogue, E. E. Arriaga and D. J. Anderton. New York: United Nations Population Fund, pp. I8-I.

Lam, D., Leibbrfandt, M., and Ranchhod, V. (2005). Labour force withdrawal of the elderly in South Africa. Centere for Social Science Research Working Paper, No I I8. University of Cape Town.

Lindley, R. M. (1988). Prospects for European labour demand. European Journal of Population, 3, pp. 383-410.

Mathers, C. D. and Schofield, D. J. (1998). The health consequences of unemployment: the evidence. Medical Journal of Australia, I68, pp. I78-182.

McLoyd, V. C. (1989). Socialization and development economy: The effects of paternal job and income loss on children. American Psychologist, 44(2), pp. 293-302.

Mroz, T. A., Savage, T. H. (2006). The long-term effects of youth unemployment. The Journal of Human Resources, 4I (2), pp. 259-293.

Ndungu, K. (2010). South Africa: labour market shuts out women. Independent Media. [On line]. Available: http://www.towardfreedom.com/home/content/ view/1946/I/.

Neugart, M. and Schomann, K. (eds). (2002). Forcasting labour markets in OECD countries: measuring and tackling mismatches. Cheltenham, UK: Edward Elgar Publishing Limited.

Preston, S. H., Heuveline, P. and Guillot, M. (200I). Demography: measuring and modelling population processes. Oxford: Blackwell Publishers.

Psacharopoulos, G. (I99I). From manpower planning to labour market analysis. International
Labour Market Review, I30(4), pp. 459.

Reinberg, A. and Markus, H. (2002). On the longterm development of qualification-specific labour supply and labour demand in Germany: empirical findings and current projection results. Mitteilungen aus der Arbeitsmarkt - und Berufsforschung, 35(4), pp. 580-600.

SADC, see Southern African Development Community.

Southern African Development Community. (201 I). Southern African Development Community: Population. [Online]. Available: http://www.sadc.int/ investment/about-sadc/socio-economic-indicators/ population/ (Accessed 201 I/I I/08).

Shryock, H. S., Siegel, J. S. and Associates. (1976). The methods and materials of demography. New York: Academic Press.

Sinz, M. (1984). Integrated population and employment projections for national-regional planning in the Federal Republic of Germany. The Town Planning Review, 55(4), pp. 420-434.

SouthAfrica.info. (20I2). South Africa's labour market. [Online]. Available: http://www.southafrica.info/ business/economy/policies/labour.html

Stats SA, see Statistics South Africa.

Statistics South Africa. (1998). The people of South Africa - population census 1996: census in brief. Pretoria.

Statistics South Africa. (2007). Community Survey 2007. Pretoria. (Statistical release P0301.)

Statistics South Africa. (200I). Census 200I. Pretoria.

Statistics South Africa. (20I I). [Online]. Available: http:// www.statssa.gov.zal

Statistics South Africa. Raw data.

Strait, J. B. (200I). The disparate impact of metropolitan economic change: the growth of extreme poverty neighborhoods, 1970-1990. Economic Geography 77(3), pp 272-305.

Strom, S. (2003). Unemployment and families: a review. The Social Service Review, 77(3), pp 399430.

United Nations. (1990). Projection methods for integrating population variables into development planning. New York. 